\title{
Conspiracy Theories by Quassim Cassam
}

\author{
Polity Press, 2021 ed., 140 pp., ISBN: 978-1509535835
}

\author{
Simon Blackburn ${ }^{1}$ \\ Published online: 28 May 2021 \\ (C) Springer Science+Business Media, LLC, part of Springer Nature 2021
}

Quassim Cassam is a notable analytic philosopher, and his book shows many of the virtues of that tradition. It is beautifully clear, thoroughly researched, rigorous and wide-ranging. Its special virtue is the care with which it distinguishes the conspiracy theories that are its topic from more everyday theories about the existence of conspiracies. Everyday theories can be the ordinary currency of historical thought, for conspiracies are common throughout human affairs. Indeed, Adam Smith famously said that whenever people of the same trade meet together, the conversation ends in a conspiracy against the public, or in some contrivance to raise prices. Cassam gives as a less sweeping example the unquestioned fact that there was a conspiracy to blow up the Houses of Parliament in 1605: the Gunpowder Plot. But the conspiracy theories that are the topic of his book are different. I shall follow Cassam by referring to them with capitals, Conspiracy Theories.

They are described as "speculative, contrarian, esoteric, amateurish, and premodern” (p. 28). They are speculative, in the sense of floating free from any solid evidence. They are contrarian, in the sense that they are contrary to the obvious explanation of events: They involve things being far from the way they appear to be. They are esoteric in the sense of proposing large-scale secrets and mysteries (Cassam's jawdropping example is the Theory that the Kennedy assassination was the work of a man who looked like Oswald, but who was not him). They are amateur, in the sense that they rely heavily on pronouncements from people who are not specialists in relevant disciplines, such as engineering, medicine or ballistics. Finally, they are premodern in the sense of echoing, or perhaps parodying, the religious belief that God's design is at work in all that happens. So things always happen for a reason, and if there is no overt motivation for something, there

Simon Blackburn

swb24@cam.ca.uk

1 Former Bertrand Russell Professor of Philosophy, University of Cambridge, Cambridge, UK must be a hidden one. Like people suffering from paranoia, the Conspiracy Theorist does not accept that sometimes stuff just happens. What happens must be happening for a reason, there must be hidden agencies at work.

Later in the book Cassam adds a sixth characteristic. Conspiracy Theories are "self-sealing". That is, the Theory becomes insulated from evidence, and immune to refutation. Evidence and reason simply bounce off the closed mind of the Conspiracy Theorist. Indeed, the more that evidence and reason stack up against it, the more the Theory is taken to be confirmed, for the more it has been given additional proof that things are not as they seem. This sets an almost impossible obstacle to engaging and changing people's minds by rational means. People are more likely just to double down, becoming more fervently convinced of the Theory, and rational argument backfires. This is of course not peculiar to outlandish convictions, for quite generally people regard their own beliefs as if they are their precious property, so that in case of attack, they need ever more careful protection.

As well as setting out these useful marks of Conspiracy Theories, Professor Cassam offers a diagnosis of their attractions to some people, and a concomitant proposal for curing them. His thesis is that they are "basically a form of political propaganda and that the response to them also needs to be political" (p. vii). He is undoubtedly right that many of the most virulent Conspiracy Theories, now and throughout history, have been concocted and promoted for political reasons. They often have the effect of demonizing a section of the population. Hitler rode to power through conspiracy theories, laying all the evils besetting Germany at the door of the Jews, gypsies and other minorities. Some Conspiracy Theories openly target those of different political persuasions, and are passionately promoted by their opponents.

Cassam argues that since this is the function of Conspiracy Theories, a principal antidote must be to work on the emotions of those who hold them. By showing, for instance, that a Conspiracy Theory is fundamentally anti-Semitic, one might shame or embarrass anyone attracted to the Theory 
sufficiently to give them pause. It would be an appeal to their emotions, not to their reason. Cassam admits candidly enough that this is only one tool amongst others, but it is the one in which he has the most faith.

Here I have a doubt, for I do wonder how effective an attempt to shame or embarrass Conspiracy Theorists would be, even in cases that the rest of us might regard as especially shameful. When Conspiracy Theories have political orientations, they are not usually hard to notice. If someone subscribes to the view that George Soros is the head of an international conspiracy of Jewish financiers bent on world domination, are they really likely to be ashamed, or even surprised, at it being pointed out that this is a vehicle of antiSemitic sentiments? If a Proud Boy buys the idea that Hilary Clinton manages a secret society of Democratic paedophiles who meet in a pizza parlour in New Jersey, are they likely to be embarrassed by being "outed" as against the Democratic party? I suspect that if anything they would revel in it, just as Klu Klux Klan members revel in their racism. I was left puzzled by which constituency Professor Cassam thinks might actually be cured by his proposal. There are others, I shall suggest, that might work better.

\section{II}

Before reading Professor Cassam's book, I had always thought that conspiracy theories were a device to make stupid people feel intelligent. They transform know-nothings into know-alls; losers into winners; those who get scoffed at into those doing the scoffing. It was not surprising, I thought, that people deluded enough to admire Donald Trump in the years of his pomp also lapped up conspiracy theories about global warming, Obama's birthplace, the 9/11 attacks, the Coronavirus, the paedophile ring in its pizza outlet in New Jersey and many others. Conspiracy Theories give people who are otherwise bewildered a passport to certainty.

In pursuit of his political diagnosis of the attractions of Conspiracy Theories, Professor Cassam downplays the idea that conspiracy theorists are "gullible, irresponsible, paranoid, stupid" (p. 1). But I do not see why these are incompatible. It seems to me quite possible that subscribing to Conspiracy Theories is the way in which people who are gullible, irresponsible, paranoid and stupid are apt to express their political attitudes.

In any case, I am also not sure that all conspiracy theories are political, except in a sense in which all action is political action. In a less embracing sense, a conviction that Bill Gates is using COVID-19 vaccines to implant microchips in people, or that $5 \mathrm{G}$ telephone masts are devices for harming the population, are not essentially political beliefs, although they can give rise to crimes against people and property. The idea that many people in the medical profession have conspired to manufacture fake reports that measles vaccines are safe is not in itself a political idea. It could generate a political movement, perhaps aimed at passing laws criminalizing swathes of modern medicine, but as far as I know, it has not. The damage it does is in the first instance private, directly putting antivaxxers themselves and their children at increased risk of disease and death, and then indirectly public, since it puts other people and their children at the same risk. It is therefore a public health desideratum to suppress the idea. A government could pass a law making it an offence to disseminate the idea, and that would be a political act, but the idea is not in itself political.

If reliance on shaming and embarrassing Conspiracy Theorists is unlikely to be very effective, what might do better? How can we stop people from living in a general miasma of mistrust, while nevertheless putting trust in untrustworthy sources? We could do worse than return to Aristotle, who said that people become virtuous by practising virtuous behaviour. Children taught in trusting families by trusted teachers will themselves be more likely to trust and to be trustworthy. Unfortunately in the USA and the UK alike, indeed in all countries in which religious stories are integrated into general education, any sceptical children will have occasion to mistrust their teachers. But can we imagine an education that might help? There is one great example to hand.

The imperturbable empiricist David Hume congratulated himself on having found an argument which will be "an everlasting check on all kinds of superstitious delusion, and consequently will be useful as long as the world endures" (Section X, Inquiry Concerning Human Understanding). The targets of Hume's argument were the stories of miracles that are plentifully scattered through religious writings and religious histories. But the argument has wider application. Put in more modern (Bayesian) clothing it reminds anyone who is told a story and wonders whether it is true to consider three things. First, are the events related in this story antecedently likely - do they conform to the way of the world as you have experienced it? Second, is the story itself what you would expect to hear if the events had happened as described? And thirdly, what other explanations might there be of the existence of this story, apart from its truth, and how probable are they?

The effect of these questions on stories of miracles is devastating. For in the nature of the case the events related need to be directly contrary to the normal course of events. It is not everyday that we see people who have had their heads chopped off picking them up and walking off carrying them, as St Denis is said to have done in Paris. Second, if someone actually did do such a thing, is the historical record what we might expect? Perhaps it is, but sometimes it is not: The historian Gibbon ironically criticizes the Roman historians Seneca and the elder Pliny for failing even to mention the miraculous darkness that is suppose to have enveloped the 
earth for $3 \mathrm{~h}$ after the crucifixion of Jesus "the greatest phenomenon to which the mortal eye has been witness since the creation of the globe" (Chapter XV, Decline and Fall of the Roman Empire). The silence of the historians diminishes confidence in the truth of the Biblical accounts.

Finally, how probable are other explanations? And here countless perfectly normal possibilities come into view. People make mistakes. People lie. People like to fool other people. People are victims of self-deception. People are prone to believe what they wish to believe. Faced with such commonplace and plausible competitors, the probability, Hume concludes, always favours some other explanation than the occurrence of the miracle related in the story.

Conspiracy Theories are not always as outlandish as stories of religious miracles. But a habit of scrutinizing their credibility would tend to the same result. Is it really probable that Jack on your Facebook group knows more about measles than the entire medical profession? Is it probable that $9 / 11$ was caused by a gigantic conspiracy of public officials with no other histories of murderous intent, without anyone giving the game away? Is it likely that a single person of doubtful sanity, strutting around in a buffalo suit, knows more about the integrity of the electoral process than the huge number of persons involved in collecting and counting the votes, none of whom corroborates his theories?

Although I would place some trust in education, I certainly would not ignore the role of emotions. An emotional involvement can be a good prelude to conversion. An anti-vaxxer who will not listen to evidence about the safety of measles vaccines may be more likely to be converted by facing the reality of dead children. The recent film To Olivia shows in heart-wrenching detail the grief and devastation of the author Roald Dahl's life when his daughter died of the disease in 1962, and I hope it gains wide currency in the anti-vax movement. I also gather that the trauma of seeing their political representatives at real risk from an armed mob gave even some Republicans pause.

A general atmosphere of trust requires trustworthiness from everyone. Unfortunately the exigencies of government, and the market, motivate many departures from the strict and literal truth. Machiavelli devoted Chapter XVIII of his book The Prince to the thesis that princes (i.e. governments) must be prepared to lie or break their word when the occasion demands it. Even in parts of science this creates serious problems. In his book about the distortions of medical science, the writer and doctor Ben Goldacre tells how reports of clinical trials give the companies sponsoring the trials what they want. In one example of fifty-six trials comparing painkillers in every case, the sponsoring manufacturer's product came out on top, implying together the logical impossibility that each of the drugs was better than all the others. ${ }^{1}$ I hope Big Pharma is redeeming itself with its apparent success in combating Coronavirus.

It is a wicked world out there. It is good to be a little sceptical. But scepticism must be even-handed. Jack on your Facebook group deserves it rather more than the combined efforts of scientists, doctors, accredited journalists and law courts.

Publisher's Note Springer Nature remains neutral with regard to jurisdictional claims in published maps and institutional affiliations.

Simon Blackburn retired from the Bertrand Russell Chair of Philosophy at the University of Cambridge in 2011, and remains a Fellow of Trinity College. He is the author of many books, including The Oxford Dictionary of Philosophy, Truth: A Guide for the Perplexed, Think and Ruling Passions.

\footnotetext{
${ }^{1}$ Ben Goldacre, Bad Science, Harper Perennial, 2009, p. 211.
} 